\title{
A COMPARISON OF SELECTED BIOMECHANICAL PARAMETERS OF FRONT ROW SPIKE BETWEEN SHORT SET AND HIGH SET BALL
}

\author{
PAPAN MONDAL ${ }^{a}$ AND SUDARSAN BHOWMICK ${ }^{\text {b** }}$ \\ ${ }^{a}$ Assistant Professor, Department of Physical Education, Jadavpur University, West Bengal-700032, India \\ ${ }^{\mathrm{b}}$ Professor, Department of Physical Education, University of Kalyani, Nadia, West Bengal 741235, India \\ *Corresponding Author Ph: 0332582 9925; Email: sudarsanbhowmick@yahoo.com
}

DOI: $10.26524 / 1311$

\begin{abstract}
Introduction: The purpose of this study was to compare the selected biomechanical parameters of front row spike between short set and high set ball for intervarsity level volleyball players.

Methods: Eight Intervarsity level male volleyball players $(22.5 \pm 2.00 \mathrm{yrs}, 1.78 \pm 0.05 \mathrm{~m}$ and $65.09 \pm 6.83 \mathrm{~kg})$ were selected as the subjects for this study from University of Kalyani and Visva-Bharati University, West Bengal, India. All subjects were right-handed volleyball players. The players were allowed to have warm-up and trials. The action of short and high set ball spiking was recorded by a digital video camera (Sony, $24 \mathrm{fps}$ ). Recorded data were analyzed with the help of power DVD software. The selected kinematics variables were approach speed, jump height, duration of flight and ball velocity. The other segmental take off angles were also be studied in this study those were ankle angle, knee angle and hip angle. The mean, standard deviation and t-test was used for statistical analysis of the data.
\end{abstract}

Result and Discussion: The results revealed that insignificant difference exists between short set and high set ball front row spike performance for intervarsity level volleyball players except jump height and duration of flight which were significantly differ for short set and high set ball front row spike.

Conclusion: This study describes the kinematic characteristics of the male volleyball short set and high set front row spike. It was noted that short set front row spike had a greater approach speed and shorter duration of flight, jump height and ball velocity than that of high set front row spike.

Keywords: Volleyball, spike, intervarsity, ball velocity

\section{Introduction:}

The volleyball game has a number of fundamental techniques of which the spike is one of the most difficult to master but demanding for high performance. Spike is the most dramatic and popular skills in volleyball which provides an exciting and dynamic skill that is captivating for players and spectators alike. The athlete is expected to jump and hit the ball with maximum force and accuracy at the approximate peak of the jump [1-7]. Analysis of this technique has become the focus of attention of biomechanical research for last a few decades. Prsala (1982) identified four phases of the spike technique: the approach, preparation, hitting, and landing [8] The approach involves two or three controlled running strides, a transitional last step to prepare for the transfer of horizontal momentum to vertical momentum, and a double footed vertical jump. In the preparatory phase, the striking arm is swung upward in an abducted and laterally rotated position. The elbow is flexed at approximately 90 degrees and the wrist is hyper- extended. During hitting phase, the shoulder is elevated; the upper arm is inwardly rotated and adducted; the forearm is extended at the elbow and the wrist is flexed. The athlete absorbs the downward momentum by flexing the joints of the lower extremities when landing. Coleman et al. (1993) studied on ten male international male volleyball players who spiked the ball in the front row at the 1991 World Students Games [9]. They reported the mean vertical velocity of the Centre of Mass (COM) at take off was $3.59 \mathrm{~m} / \mathrm{s}$ and height of the jump was $0.62 \mathrm{~m}$. Saunder (1980) studied the effects of approach speed on one and two-foot vertical jump performances [10]. He found that vertical velocities of two-foot jump peaked when the approach speed was up to 50-60\% of maximum sprint speed and the vertical velocities of one-foot jumps were up to 60-70\% of maximum sprint speed. It is important to understand the mechanical factors, which contribute to the successful spiking action. The purpose of this study was to analyze the selected kinematic 
factors - approach speed, jump height, duration of flight, ball velocity and segmental angles during takeoff in front row spike performed by male volleyball players. Therefore, it was the aim of this study to provide descriptive kinematics of some of the biomechanical factors involved in the front row spike.

\section{Methodology:}

The principal method used is comparative kinematics method, aimed at finding the differences in Kinematics variables purpose in gaining information of front row spike performance between short set and high set ball.

Selection of Subject:

A total eight (8) Intervarsity male volleyball players were taken as the subject for the study from the Visva-Bharati University and University of Kalyani. The mean age, height and body weight of intervarsity players were 22.5 years $( \pm 2.00)$, $1.78 \mathrm{~m}( \pm 0.05), 65.09 \mathrm{~kg}( \pm 6.83)$ respectively. All subjects in this study were right-handed volleyball players. They all were healthy and don't had any injury reported within the last year.

Tools and Equipments:

For the purpose of this study a high speed video camera (Sony, 24fps), camera tripod, measuring tape, marking powder, volleyballs, volleyball court, motion analysis software (power DVD) and computer system were used.

Procedure for Data Collection:

For the kinematical data a high speed video camera (Sony, 24fps) was used to capture the spike performance. Data was collected from the movement of the spiking action for each subject. The camera was placed perpendicular at a distance of $10.50 \mathrm{~m}$ on the left side of the players mounted at a height of $1.30 \mathrm{~m}$ above the ground and capture video clips of sufficient coverage to clearly see the spike process. All subjects performed five officially allotted spikes but the best one (successful) spike was selected for further analysis for measuring the selected kinematic parameters using freeze frame technique. After projecting a particular frame the stickman configuration was drawn from the each frame. Distance and time information were obtained from the _kinegram' and the camera frequency respectively. Velocity of movement was calculated as the first derivative time of (Distance-time) information. Time information was obtained from the frequency of the camera (24fps).The selected kinematics variables were approach speed, jump height, duration of flight and ball velocity. The other selected parameters were ankle angle, knee angle, and hip angle during the take off phase.

Result:

The result of the statistical analysis revealed that there was no significant differences exist between short set and high set ball front row spiking in respect to approach speed and ball velocity whereas there was a significant difference exist between short set and high set ball front row spiking in respect to the duration of flight and jump height. It has showed that the calculated $t$ values of approach speed and ball velocity were less than tabulated t value (2.36) at 0.05 level of significance with 7 degree of freedom. The result of the statistical analysis of front row spike revealed that there was no significant difference exists between short set and high set ball in all the variables studies presented in table-3 (ankle angle, knee angle and hip angle during takeoff). It has showed that the calculated $t$ values of approach speed and ball velocity were less than tabulated $t$ value (2.36) at 0.05 level of significance with 7 degree of freedom.

Discussion: It was the aim of this study to examine the mechanical factors between short set and high set ball front row spike. The result of the present study indicated that there were no significant differences between short set and high set ball front row spike in the approach speed and ball velocity whereas there were significant differences between short set and high set ball front row spike in the jump height and duration of flight. Further insignificant differences were found between these two types of set in case of different body joint angles (ankle, knee and hip). This might be due to the fact that the variation in the approach speed and ball velocity of short set and high set ball front row spike is very less. Secondly the angle of the segments during takeoff between short set and high set ball may be same but the movement forces applied on the ball may be differ and not dependent on the angle of segment but on the speed of change of angle which was return increase the velocity of segment to 
transfer to the ball. It was clearly noted that there was differences in mean values of speed of approach for short and high set ball spiking but this difference was not statistically significant. This result was perhaps due to the fact that in this case the length of approach was considerably small in the case of short set ball spiking. In the spike for high set ball the ball was set about more than $4 \mathrm{ft}$. above the net. In order to get the ball and spike it forcefully the spikers has to achieve the greater jump height than the short set ball spike. In duration of flight mean values were difference from one another, the minimum value $(0.64 \mathrm{~s})$ was for the spike of short set ball and the maximum value $(0.70 \mathrm{~s})$ for the spike of height set ball. In case of spike for high set ball the body achieved greater vertical distance. So the ascending time was more than the short set spike and consequently the descending time is also greater and as a result the duration of flight is more in case of spike for high set ball.

\section{Conclusion:}

On the basis of the results obtained in the present study, the following conclusions were drawn:

i. The short set front row spike involves a greater approach speed and a shorter duration of flight than those of high set front row spike.

ii. The high set front row spike has a greater jump height than that of short set front row spike.

iii. The high set front row spike has a greater spiked ball velocity than short set front row spike.

Figure 1: Showing Comparison of Approach Speed, Jump Height, Duration of Flight and Ball Velocity between Short Set and High Set Ball Front Row pike
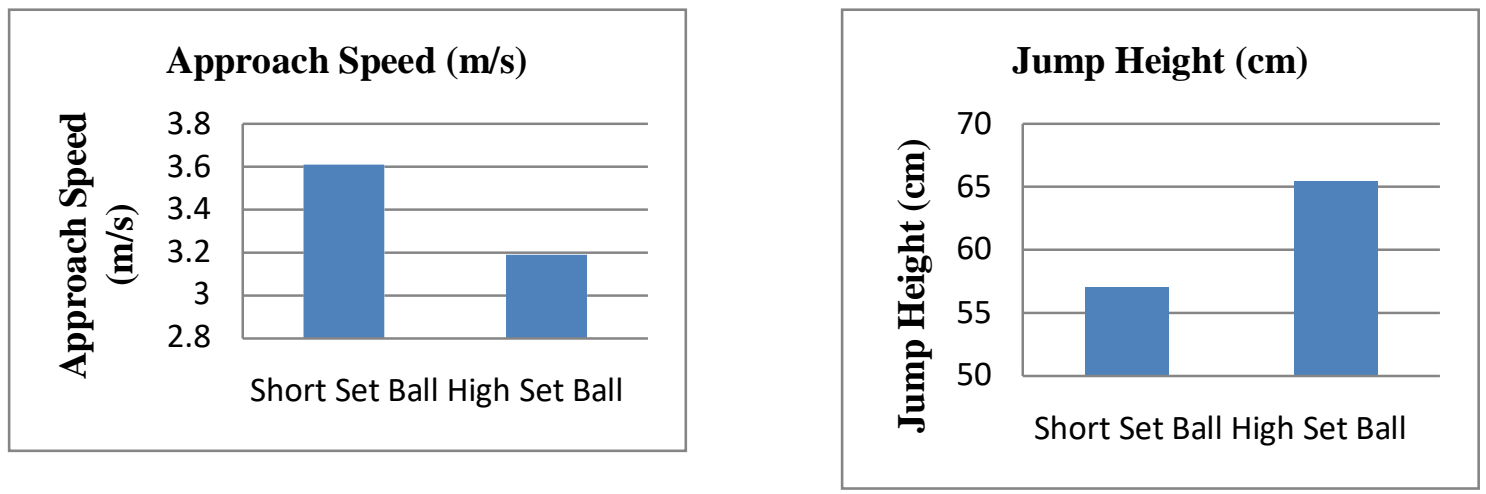

Figure 2: Showing Comparison of Different Joint Angles at Takeoff between Short Set and High Set Ball Front Row Spike.
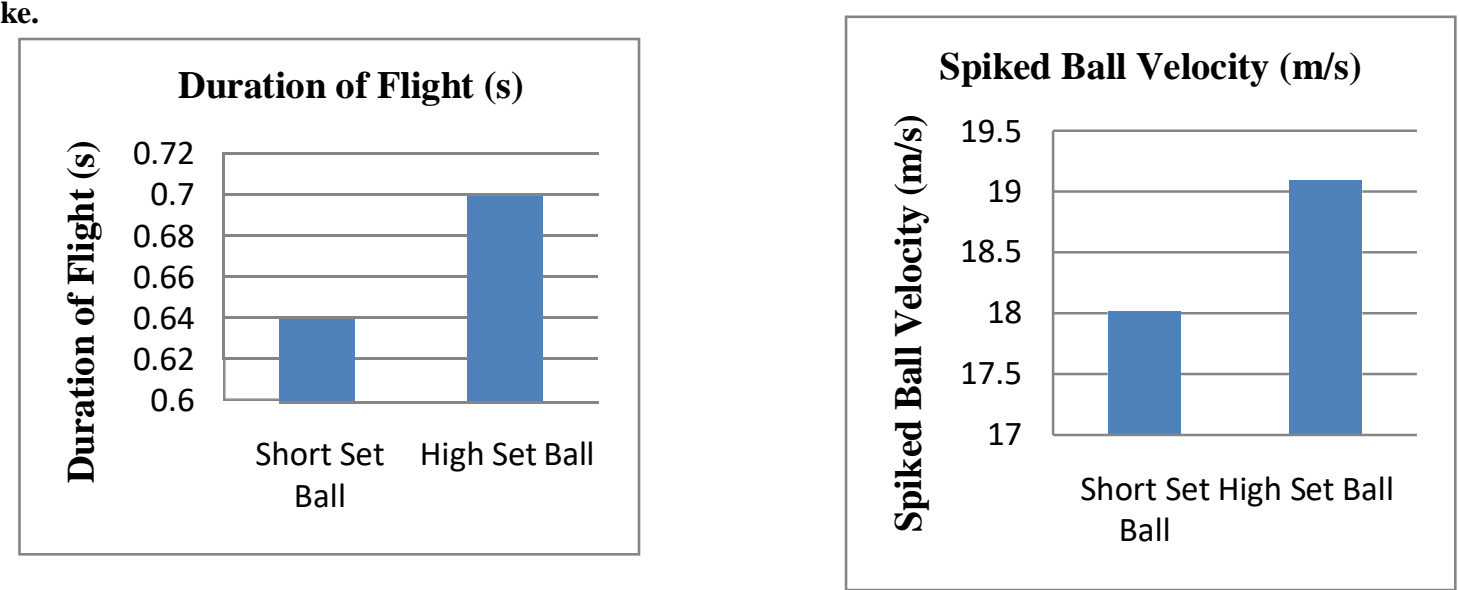


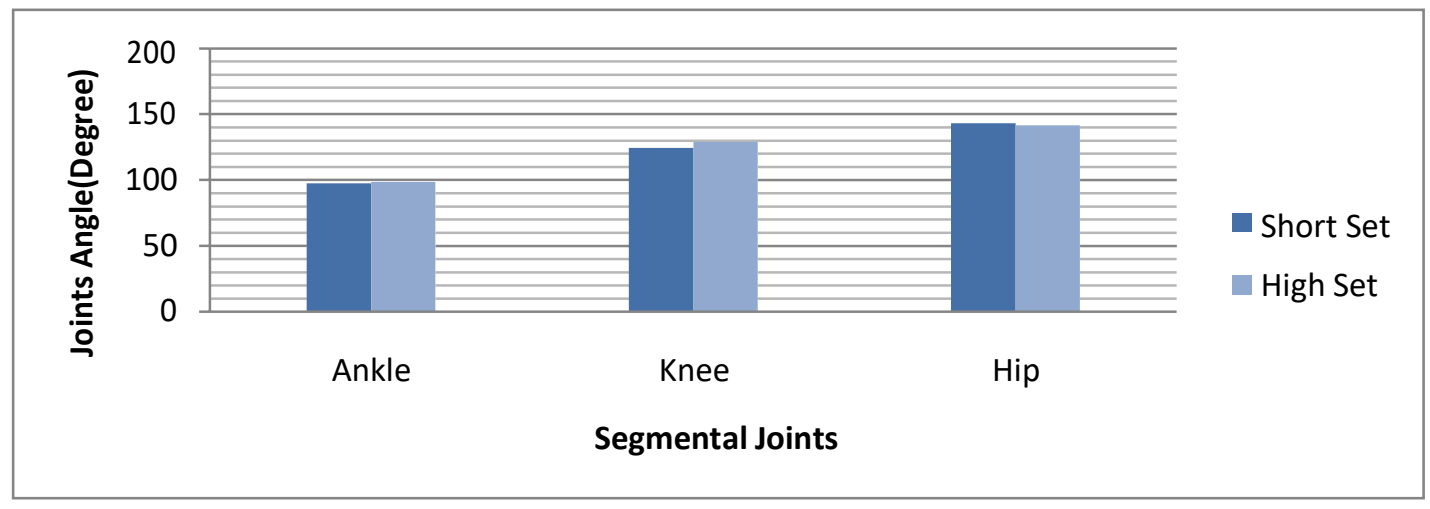

Table 1: Mean Age, Height and Weight of the Subjects (n=8).

\begin{tabular}{|l|l|l|l|}
\hline Parameter & Minimum & Maximum & Mean \pm SD \\
\hline Age(Years) & 19.00 & 25.00 & $22.50 \pm 2.00$ \\
\hline Height(M) & 1.70 & 1.85 & $1.78 \pm 0.05$ \\
\hline Weight(Kg) & 58.70 & 79.18 & $65.09 \pm 6.83$ \\
\hline
\end{tabular}

Table 2: Indicating Mean, Standard Deviation and $t$ Values of Selected Biomechanical Parameters of Front Row Spike Performance between Short Set and High Set Ball.

\begin{tabular}{|l|l|l|l|l|l|l|}
\hline \multirow{2}{*}{$\begin{array}{l}\text { Biomechanical } \\
\text { Parameters }\end{array}$} & $\begin{array}{l}\text { Short Set Ball } \\
\text { Spiking }\end{array}$ & \multicolumn{2}{l|l}{$\begin{array}{l}\text { High Set Ball } \\
\text { Spiking }\end{array}$} & \multirow{2}{*}{ Cal.t } & \\
\cline { 2 - 6 } & Mean & SD & Mean & SD & & \\
\hline Approach Speed(m/s) & 3.61 & 0.39 & 3.19 & 0.80 & 1.87 & 0.104 \\
\hline Duration of Flight (s) & 0.64 & 0.06 & 0.70 & 0.02 & 2.94 & 0.021 \\
\hline Jump Height(cm) & 56.99 & 4.49 & 65.40 & 2.48 & 6.78 & 0.000 \\
\hline Spiked Ball Velocity (m/s) & 18.02 & 3.20 & 19.09 & 1.98 & 0.81 & 0.442 \\
\hline
\end{tabular}

*Required value for being significant $-\mathbf{0 . 0 5}=\mathbf{2 . 3 6}$ and $\mathbf{0 . 0 1}=\mathbf{3 . 5 0}$

Table 3: Indicating t Values of Selected Body Joint Angles during Takeoff for Short Set and High Set Ball Front Row Spiking.

\begin{tabular}{|l|l|l|l|l|l|l|}
\hline \multirow{2}{*}{ Segmental Angle } & \multicolumn{2}{|l|}{ Short Set Ball Spiking } & \multicolumn{2}{l|}{$\begin{array}{l}\text { High Set Ball } \\
\text { Spiking }\end{array}$} & \multirow{2}{*}{ P-Val.t } \\
\cline { 2 - 6 } & Mean & SD & Mean & SD & & \\
\hline Ankle Angle (Degree) & 97.50 & 10.06 & 98.50 & 15.55 & 0.16 & 0.880 \\
\hline Knee Angle (Degree & 124.38 & 17.28 & 128.88 & 11.91 & 0.67 & 0.526 \\
\hline Hip Angle (Degree) & 143.13 & 12.91 & 141.63 & 16.70 & 0.38 & 0.710 \\
\hline
\end{tabular}

* Required value for being significant $-\mathbf{0 . 0 5}=\mathbf{2 . 3 6}$ and $\mathbf{0 . 0 1}=\mathbf{3 . 5 0}$ 


\section{References:}

[1] J. W. Bunn, (1972) Scientific principles of coaching, Englewood Cliffs, N.J, Prentice Hall Inc,

[2] G.H.G Dyson, (1977) The Mechanics of Athletes (7th ed.). New York, New York: Holmes \& Meier,

[3] Endo Toshiro et al. (2008), A biomechanical analysis of pipe spike motion for elite male volleyball players in official games, ISBS Conference 2008, July 14-18, 2008, Seoul, Korea.

[4] J.G. Hay, J.G. Reid, (1982). The Anatomical and Mechanical Bases of Human Motion. Englewood Cliffs Nz: Prentice-Hall,

[5] C.F. Huang, G.C. Liu, T.Y. Sheu, (1998) A three dimensional analysis of the volleyball one-foot jump spike, ISBS‘98-Proceeding II.

[6] Kuhlman Class et al. (2007). Aspects of a three dimensional motion analysis of the volleyball spike in high level competition. XXV ISBS Symposium 2007, Ouro Preto-Brazil.

[7] J. Samson and B. Roy, (1976) Biomechanical analysis of the volleyball spike. In Biomechanics V-B (edited by P. Komi), pp.332-336. Baltimore, MD. : University Park Press.

[8] J. Prsala, Improve your spiking in volleyball, C. V. A. Volleyball Technical Journal, 7 (1982) 57-64.

[9] S. Coleman, A. Benham, S. Northcott, A Three-Dimensional Cinematographical Analysis of the Volleyball Spike, Journal of Sports Sciences, 11(4) (1993) 259-302.

[10] H. L. Saunder, (1980) A cinematographically study of the relationship between speed of movement and available force, (Unpublished doctoral dissertation) Texas A \& M University, College Station. 